\title{
Political Campaigning 2.0: The Influence of Online News and Social Networking Sites on Attitudes and Behavior
}

\author{
Montathar Faraon \\ School of Natural Sciences, Environmental Studies and Technology, Södertörn University, S-141 89 Huddinge, Sweden. \\ E-mail/phone: montathar.faraon@sh.se, +46 (0)73 5669727.
}

\section{Georg Stenberg}

Centre for Psychology, Kristianstad University, S-291 88 Kristianstad, Sweden. E-mail/phone: georg.stenberg@hkr.se,+46 (0)76 8179795.

\section{Mauri Kaipainen}

School of Natural Sciences, Environmental Studies and Technology, Södertörn University, S-141 89 Huddinge, Sweden. E-mail/phone: mauri.kaipainen@sh.se, +46(0)70 7670351.

\begin{abstract}
This study aimed to examine differences in influence between online news (e.g., New York Times) and social networking sites (e.g., Facebook and Twitter) on attitudes in political campaigns. In a web-based experiment, campaign, polls and election between two fictitious candidates were simulated. Participants' explicit and implicit attitudes as well as voting behavior were assessed using self-report items and the Implicit Association Test (IAT). The results reveal that information emanating from online news had a significant influence on explicit and implicit attitudes while that of social networking sites did not. Overall, negative items had a stronger impact than positive ones, more so in online news compared to social networking sites. Negative information from either type of media was more likely to change participants' explicit attitudes in a negative direction and as a consequence also change their vote. Practical implications of the findings and limitations of the study are discussed.
\end{abstract}

Keywords: online news, social networking sites, attitudes, political campaign, Implicit Association Test, Facebook, Twitter

Acknowledgement: The authors would like to thank Magnus Sahlberg for his time and assistance in the construction of the web-based experiment. It is also a pleasure for us to thank Jenny Vinterfrost and Aino Järveläinen for their support and comments during the development of the experiment.

T

he perception of political candidates' personality or character traits plays a central role in an electoral process (Funk, 1999; Renshon, 1996). As observed by Caprara and Zimbardo (2004), this has become such an important part of election campaigns that politicians and their marketing managers are often more focused on presenting a captivating persona than endorsing a specific political ideology.

For a long time, journalistically edited media such as newspapers, TV, and radio companies were the primary platforms during political campaigning and studies have shown that they impact public attitude (Daekyung \& Johnson, 2006; Larry, Mary, \& Richard, 2008; Spiro, 2001; Townera \& Dulioa, 2011). Large amounts of money have been spent on advertisements in these media with the aim of impacting public attitudes towards political candidates (Campus, Pasquino, \& Vaccari, 2008; Glynn, Huge, Reineke, Hardy, \& Shanahan, 2007; Martin, 2008). Campaign managers and public relations staffs use these media to shape a positive view of their candidates on traits such as honesty, credibility and judgment, while using negative advertisements against opponents. Studies have shown that the perception of political candidates' personality or character traits make a unique contribution to voting behavior that cannot solely be explained by party affiliation (Pillai, Williams, Lowe, \& Jung, 2003). 
However, some studies have shown that the Internet and other online sources such as nonjournalistic blogs are perceived as credible to an extent that nearly equals to (Qing \& Oyedeji, 2011) and in some cases surpasses that of journalistically edited media (Johnson \& Kaye, 1998; Johnson, Kaye, Bichard, \& Wong, 2007; Mackay \& Lowrey, 2007). This has led political candidates to become increasingly interested in exploiting the Internet and particularly non-journalistic resources such as social networking sites (e.g., Facebook and Twitter) as channels for political campaigning (Gil de Zuniga, Puig, \& Rojas, 2009; Utz, 2009; Zhang, Johnson, Seltzer, \& Bichard, 2010). The advantages of using social networking sites over journalistically edited media are several. For instance, they allow: (1) interaction between political candidates and voters; (2) expansion of viewership through viral distribution of material, and finally, (3), the distribution of news and perspectives unavailable to or disregarded by traditional media outlets (Mirandilla, 2009).

Despite an increased number of investigators studying the use of social networking sites in political campaigns such as the 2005 German Federal Election (Albrecht, Lubcke, \& Hartig-Perschke, 2007), the 2007 Nigerian General Elections (Ifukor, 2010), the 2008 US Presidential Election (Borins, 2009; Hanson, Haridakis, Cunningham, Sharma, \& Ponder, 2010), and the 2010 Philippine Presidential Election (Mirandilla, 2009), very little effort has been made to investigate potential differences in attitudinal impact between journalistically edited online news, henceforth known as online news, and social networking sites. Thus, the primary objective of this study is to compare the differences in influence between online news (e.g., New York Times) and social networking sites (e.g., Facebook and Twitter) on attitudes in political campaigns.

\section{Explicit and Implicit Measures of Attitudes}

Attempts to reliably measure attitudes towards political candidates have been limited by an exclusive reliance on explicit measures, such as surveys. Social desirability can bias these responses and reduce their validity (e.g., Derzon \& Lipsey, 2002; Slater \& Kelly, 2002). Furthermore, underlying attitudes may not be entirely aware to the person questioned and accessible to direct questioning. For this reason, it is important to measure both explicit and implicit attitudes. Explicit attitudes are those that are consciously accessible and can be assessed using self-report measurements (Schwartz, Vartanian, Nosek, \& Brownell, 2006), while implicit attitudes represent unconscious evaluations that people are unaware of having, but which however sometimes communicating (Greenwald, McGhee, \& Schwartz, 1998; Rydell \& McConnell, 2006). The relatively new methods of assessing implicit attitudes provide another dimension of understanding attitudes towards political candidates (Nevid \& McClelland, 2010). For instance, it has been shown that implicit measures of political attitudes are good predictors of voting behavior (Arcuri, Castelli, Galdi, Zogmaister, \& Amadori, 2008).

Empirical studies have shown that explicit and implicit attitudes account for different aspects of behavior such as deliberate and self-presentational for the former (Jellison, McConnell, \& Gabriel, 2004) versus spontaneous and nonverbal for the latter (McConnell \& Leibold, 2001). These observations have been linked to the idea that attitudes arise from two different reasoning systems used when evaluating information. According to Sloman (1996), there are two independent systems of reasoning in the brain that differ in the way they process information: the slow-learning system and the fast-learning system. The former is an associative system that uses interconnected associations in memory based on similarity and contiguity. These associations are developed and formed over time. The latter is rule-based and operates by using logic and symbolic representations on a moderately high level of cognitive processing. In addition, it has been suggested that explicit attitudes form and change according to the fast-learning rule-based system, indicating that people can occasionally control their expression of explicit attitudes, whereas implicit attitudes shape and develop according to the slow-learning associative system (Smith \& DeCoster, 2000). Although explicit and implicit measures have a tendency to be correlated, each one of them assesses specific sources of variance that cannot be explained by a single factor (Cunningham, Preacher, \& Banaji, 2001). 
Moreover, the difference between explicit and implicit attitudes has been evident in the political domain. For instance, Nevid and McClelland (2010) examined explicit and implicit attitudes towards Barack Obama during the 2008 presidential election race. Obama's image in the photographs was manipulated in terms of darkness to accentuate racial cues. The results revealed significant differences in explicit and implicit attitudes towards Obama between self-identified conservative and liberal participants. Regarding the implicit attitudes, those who identified themselves as conservative had a stronger associational negative bias against darker images of Obama compared to their liberal counterparts, whereas there were no differences between groups when lighter-colored images were used. As expected, liberal participants were more positive in their explicit attitudes than those who identified themselves as conservative.

From these considerations, we derive the prediction that explicit and implicit attitudes may both influence the final decision the voter makes, i.e. which candidate to vote for. In our experimental study, we measure both types of attitudes and present experimental manipulations consisting of positively and negatively valenced information designed to affect them in different ways.

\section{Valence of Information in Political Campaigns}

A growing body of research concerning the effect of media in political campaigns has focused on advertisements, especially on television adverts (Kaid \& Johnston, 2001). Much of the research concerning political advertisements has focused on the effects of positively and negatively valenced information, i.e. information that has either a positive or negative denotation. Empirical studies have revealed that positive information about political candidates is likely to increase their level of support (Lau, Sigelman, \& Rovner, 2007), likeability, and number of received votes (Wu \& Dahmen, 2010).

However, the focal point in a great number of studies concerning political campaigns has been on negative information because of its detrimental effects, dramatic character, ability to persuade voters, and the tendency to demoralize political candidates (Ansolabehere, lyengar, \& Simon, 1999; Carraro, Gawronski, \& Castelli, 2010; Fridkin \& Kenney, 2011). It has been argued by Lau (1985) that two types of negativity effects related to perception and motivation affect political candidates. The former indicates that negative information is more likely to be perceived and evaluated than comparable positive information, increasing the likelihood of getting a message through (Peeters \& Czapinski, 1990; Skowronski \& Carlston, 1989). The latter is based on an evolutionary assumption that it is more advantageous to avoid costs rather than reach for gains (Kahneman \& Tversky, 1979; Lau \& Pomper, 2002).

While it has been reported that the electorate in political campaigns attends to negative information more than to comparably extreme positive information (Carraro, et al., 2010), negative information could also lead to a backlash effect caused by factors such as lack of source credibility (Jasperson \& Fan, 2002) and overflow of negative adverts (Shapiro \& Rieger, 1992). Despite this discrepancy, political candidates and public relations staff continues to believe in the negative effect of advertisement in political campaigns, as observed by Trent and Friedenberg (2002). Thus, based on the weight of the evidence, we expect a superiority of negative over positive information in the effects on both explicit and implicit attitudes as well as on the behavior they help determine.

\section{Source and Attentional Processing}

Does the medium matter in attitudinal change during political campaigns? Findings are mixed and a number of studies show that the Internet has a significant influence on attitudes in the political domain (e.g., Castells, 2001; Shah, McLeod, \& Yoon, 2001), whereas others argue that the Internet has limited effects on political attitudes (Bimber \& Davis, 2003; Katz \& Rice, 2002). What accounts for these differences? One possibility is that many fail to discriminate among the variety of Internet sources (e.g., YouTube, Facebook, Twitter, online newspapers, web sites of political candidates and television networks, blogs, and others). 
Studies have reported that the source of information plays a crucial part when evaluating the credibility of information (Kalbfleisch, 2003). A number of studies in the political domain concerning the credibility of online sources have focused on blogs (e.g., Carlson, 2007; Johnson \& Kaye, 2010; Mackay \& Lowrey, 2007) and online news versus their traditionally delivered counterparts such as printed newspapers and television news (e.g., Daekyung \& Johnson, 2006; Johnson \& Kaye, 1998; Larry, et al., 2008; Spiro, 2001). However, it is uncertain whether online news is perceived as more credible compared to their traditional counterparts in political campaigns.

Daekyung and Johnson (2006) have shown that a majority of politically interested web users (71.1\%) relied more on online news than newspapers and television. Online news significantly and positively predicted political involvement, political interest, campaign interest, and likelihood of voting. In fact, other researchers found that those who consumed online news for political information were more predisposed to vote in the 1996 and 2000 US presidential elections (Tolbert \& Mcneal, 2003). Furthermore, a study by the Pew Research Center (2011) reveals that $24 \%$ of American adults get campaign information from the Internet during the 2010 midterm elections, more than a three-fold increase from the 7\% during the 2002 midterm elections. Over the same time, the proportion of Americans using newspapers has fallen from $33 \%$ in 2002 to $27 \%$ in 2010 while for television it has remained stable from $66 \%$ in 2002 to $67 \%$ in 2010. In Sweden, the Internet and personal contacts (i.e., friends, family and work colleagues) have become the most important sources of information, surpassing other media (e.g., TV, newspaper and radio). This applies primarily to young people (age 12-25) while middle-aged (age 46-55) consider all media to be equally important (Findahl, 2012).

In contrast, Kononova, Alhabash, and Cropp (2011) examined the effects of print, television and online news on political socialization during the 2008 U.S. presidential election. Acquiring news from newspapers and television predicted intentions to participate in American politics but no significant results were found for online news. Their findings also show that newspapers hold the highest position in credibility, followed by online news and television.

The different outcomes could be explained by the varying degrees of attention people give to different media. According to Townera and Dulioa (2011), online news is considered to be more credible than social networking sites, and high credibility sources are given more attention, which leads to more explicit processing. Persuasion is less effective if sources are given less attention and less credibility (Chaiken \& Maheswaran, 1994; Petty, Briñol, \& Priester, 2009; Tormala, Briñol, \& Petty, 2006). Concerning implicit processing, information from social networking sites is often consumed with less attention and is therefore more likely to impact implicit rather than explicit attitudes. In turn, this could influence political behavior (e.g., voting) because both implicit and explicit attitudes can direct behavior alone or in interaction (Perugini, 2005).

Although a limited number of studies have investigated the effects of social networking sites in a political context (e.g., Townera \& Dulioa, 2011; Utz, 2009), very little attention has been given to examining the relationship between online news and social networking sites vis-á-vis explicit and implicit attitudes in political campaigns. Utz (2009) found that the Dutch social networking site Hyves influenced participants' explicit attitudes in favorable ways towards political candidates. Viewing a political candidate's online profile strengthened existing attitudes and right-wing politicians who reacted on voters' comments were perceived more favorably than their left-wing counterparts. Overall, the study suggests that interacting with prospective voters on a platform that is a part of their daily life could be a way of increasing political involvement.

Moreover, different types of online sources such as YouTube, Facebook, television network sites, and presidential candidate websites, seem to produce different effects on political attitudes. Findings by Townera and Dulioa (2011) suggest that social networking sites featuring usergenerated content did not generate high levels of trust in participants but a mainstream media site, abcnews.com, did. In terms of voting behavior, those who viewed material on YouTube and Facebook compared to those in other conditions (i.e., television network sites and presidential candidate web sites) were more likely to vote in the 2008 U.S. presidential election. Finally, it was suggested 
that social networking sites were perceived as less credible compared to online news media because the latter are known for their expertise, credibility and quality in the editorial process.

Given the distinct characteristics of social networking sites-particularly social interaction, viral distribution of information, and publication of news that is unavailable in corporate-controlled media-it is important to examine whether information dissemination in social networking sites will be perceived and evaluated with equal weight as that of online news with regards to implicit and explicit attitudes.

\section{Aim and Study Hypotheses}

Political candidates invest many resources in social networking sites with high expectations about their influence to persuade voters. However, most of these investments are typically made without knowledge grounded in independent research about how social networking sites influence attitudes and behavior in political campaigns. Past research concerning this matter is limited in scope, i.e. accounts only for explicit attitudes, and relies to a great extent on surveys where social desirability bias is an issue. While it has been shown that social networking sites are perceived as less credible compared to online news, it is unknown whether this holds true for implicit attitudes and voting behavior. From these considerations, the current study aims to expand the aforementioned scope by experimentally assessing the differences in influence between online news and social networking sites on explicit and implicit attitudes as well as voting behavior.

Further, a secondary point of interest is to examine how the negative valence effect, i.e. the advantage for negative over positive information, plays out in online news and social networking sites. While a growing body of research suggests that negative information is given more attention than comparable positive information, it is not clear whether this holds to the same extent for both types of media. We can assume that wariness against less credible sources could result in greater caution with negative items. Sensational information is probably believed only when backed by a trusted source, whereas the mundane can be accepted from any source. Past research and the aforementioned considerations lead us to form the following hypotheses:

- H1: Online news will have greater leverage and more extensive influence on explicit and implicit attitudes as well as voting behavior compared to social networking sites.

- H2: The negativity effect on explicit and implicit attitudes will be weaker in social networking sites compared to that of online news.

To test these hypotheses, a web-based experiment was conducted that staged a mock campaign. Politically interested Swedish online users were presented with two fictive political candidates from an English-speaking, non-descript country. The candidates were briefly described in vignettes designed to elicit left-right attitude differences. Participants made an initial choice and were then exposed to media content, which consisted of items that could plausibly be used during a political campaign. Items were systematically varied (see further 5.4 ) in the extent to which they favored the participant's initially preferred candidate. Items were written for a specific medium and could not easily be migrated to another. For direct comparisons of effects of media this brings difficulties of interpretation, making item effects a possible confound. Fortunately, as our results show, item effects did not constitute an issue.

\section{Method}

\subsection{Participants}

Invitation to participate in a web-based experiment was distributed by a mailing list to politically interested Swedish online users. A total of 139 participants provided complete records. They made a choice between participating anonymously and without compensation or having more than a 50 
percent chance to win a cinema ticket by providing their e-mail address. The distribution of cinema tickets necessitated the partial waiver of anonymity. After applying exclusion criteria (see data processing) a group of 122 remained, 66 men and 56 women, aged between 16 and 79 years $(M=$ 35.65; $S D=13.62$ ). Participants were asked to give information on their political preferences among Swedish parties. Response alternatives were 10 political parties in the latest parliamentary election, with the added alternatives: "did not vote", "voted blank", "no party sympathy", and "decline to respond".

In the analysis, the 14 alternatives were subsumed under three groups, constituting a somewhat simplified picture of the political landscape in Sweden: the governing Liberal-Conservative Alliance (this study: $31.1 \%$ versus 2010 General Election: 49.4\%) [Moderate Party, Centre Party, Liberal People's Party, and Christian Democrats], the Red-Green Opposition (this study: $46.7 \%$ versus 2010 General Election: 43.6\%) [Social Democratic Party, Green Party, and Left Party of Sweden], and others (this study: $22.1 \%$ versus 2010 General Election: $7 \%$ ) [the three extra-parliamentary parties, and the responses "did not vote", "voted blank", "no party sympathy", and "decline to respond"].

\subsection{Material}

Participants' explicit attitudes were assessed using self-report items and their implicit attitudes were assessed using the Implicit Association Test (IAT) (Greenwald, et al., 1998; Greenwald, Nosek, \& Banaji, 2003).

The measurements in the IAT are defined in terms of association strengths. Participants respond to a series of items that are to be classified into four categories, two representing a concept discrimination such as police versus criminals and two representing an attribute discrimination such as moral versus immoral. The IAT measures are interpreted in terms of association strengths by assuming that participants respond more rapidly when the concept and attribute mapped onto the same response are strongly associated (e.g., police and moral) than when they are weakly associated (e.g., criminals and moral). The concept discrimination pair in the current study was two political candidates, Mike Baker and Samuel Johnson, and the attribute discrimination pair was positive (e.g., honest) and negative (e.g., incompetent) adjectives. The experiment consisted of five parts: introduction, pre-measurement, experimental condition, post-measurement, and debriefing. Explicit and implicit attitudes were both measured in the pre- and post-measurement.

The introduction included information about the purpose of the experiment, expected time to complete it, and base information about two political male candidates, Mike Baker and Samuel Johnson. The former was portrayed as right-of-center, in most European countries corresponding to a liberal conservative, in the UK corresponding to Tory, and in the USA corresponding to a moderate Republican. The latter was portrayed as left-of-center, in most European countries corresponding to a social democrat, in the UK corresponding to Labour, and in the USA corresponding to a Democrat.

Pre-measurement gathered demographics about the participants such as age, gender as well as self-declared political allegiance, and measured explicit and implicit attitudes. The explicit attitudes measurement consisted of three questions and included asking participants to indicate whom of the two political candidates they would vote for if there were an election today and to rate on a Likert scale how they perceived each candidate. The questionnaire was composed of eight items and ranged from 1 (disagree) to 4 (agree). Items consisted of both positive (e.g., honest) and negative (e.g., incompetent) adjectives.

Following Greenwald, et al. (1998), the IAT was obtained from the Inquisit Task Library and consisted of 180 trials divided into 5 blocks and 2 practice blocks. It was composed of 32 stimuli: 8 photos of each political candidate, 8 positive adjectives (e.g., honest) and 8 negative adjectives (e.g., incompetent).

In line with Carraro et al. (2010), the experimental condition consisted of 48 news items that were equally divided between online news (e.g., New York Times) and social networking sites 
(e.g., Facebook and Twitter). Each subset of 24 items was in turn divided into items of positive and negative valence. An item consisted of three parts, namely a picture of the candidate to which it referred, a logo indicating the source of the item and finally the item content. The style, tone and length of each item was adapted to the alleged source, for instance Twitter items were limited to 140 characters. The presentation of each item was divided into two sections, left and right, the picture of the candidate to the left and the logotype heading the item content. For an example as well as the complete list of sources used (i.e., the adjectives used in the IAT, the full item content, and the logotypes) can be found at: http://www.distans.hkr.se/fam/social/.

Post-measurement measured participants' explicit attitudes in a similar way as the premeasurement with the exception that no demographics were collected. For the implicit attitudes, a brief IAT by Sriram and Greewald (2009) was adopted to avoid mental fatigue effects (Boksem, Meijman, \& Lorist, 2005; Webster \& Richter, 1996) and consisted of 100 trials equally divided into 5 blocks.

In the debriefing, participants were thanked for their commitment and for participating in the research experiment.

\subsection{Procedure}

Participants completed the entire experiment online using a computer. At the beginning of the experiment, they were given introductory instructions and read information about the political candidates. The presentation order of the candidates was pseudo-randomly determined, as was the order of the presentation of the base information about political candidates, the voting and the rating of political candidates in the explicit attitudes measurements.

Next, they completed items for the demographics and the pre-measurement explicit attitudes. Following that, they were given instructions on how to complete the pre-measurement IAT. This was conducted according to the standard procedure recommended by Greenwald et al. (1998). Then, a total of 32 news items were presented and in order to proceed to the next item the participant had to rate the news item on a 3-point Likert-type scale: "the item changes my previous view of the candidate" (change), "the item does not affect my view of the candidate" (indifference), and "the item strengthens my previous view of the candidate" (confirmation). In the post-measurement, the participants repeated the same procedure as in the pre-measurement with the exception of a shorter IAT as recommended by Sriram and Greewald (2009). With the post-measurement completed the participants participation in the experiment and where were thanked for their commitment.

\subsection{Study Design}

The layout of the study was a two-factor completely randomized between-subjects design. The two factors comprised systematic variation in content of two types of media, online news versus social networking sites. Thus, for each type of media, content favorable for the preferred candidate was presented in the proportions 25,50 or 75 per cent, which made the complete design $3 \times 3$ levels. Each participant was randomly assigned to one of the resulting 9 conditions.

From the total pool of 48 news items, each participant was randomly assigned a selection of 32 items composed of equal proportions of media type (online news versus social networking sites) and valence (positive versus negative). As can be seen in the complimentary material, media type was indicated by a logo for each item. Positive items described laudable actions performed by the protagonist, or likeable views expressed by him. Negative items described unethical or embarrassing behavior, or uninformed or bigoted views.

The selection of items and assignment to candidates was made pseudo-randomly under the constraint that the proportions of items were determined by the participants' id-number according to Table 1. The selection algorithm ensured that each item hade an equal probability of being used across participants. 


\subsection{Experimental Condition}

Each participant read 32 items, 16 from each type of media. Of the 16 items, half were positive in content and the other half negative. Critically, we varied which candidate was the protagonist of the news items. Thus, in the first condition 75 per cent of the online news content was positive in relation to the preferred candidate $(P)$ by ascribing 6 of positive items to him and 2 positive items to his opponent, i.e. the non-preferred candidate (NP). The 8 negative items were divided between the candidates, so that 2 negative items were ascribed to the preferred candidate and 6 negative items to the non-preferred candidate. This was designed to create a dominant impression of one candidate as being superior to the other without selecting exclusively either good or bad news. Similarly, a condition with equally balanced news (50/50) was created as well as a mirror image of the first condition, in which the proportions of good and bad news ascribed to each candidate were reversed. In the same way, three item distributions were created for the social networking sites. By complete crossing of these $3 \times 3$ item distributions, the nine conditions of Table 1 arose.

Table 1: Distribution of item content in the nine experimental conditions.

\begin{tabular}{|l|llllllll|}
\hline Media & \multicolumn{4}{|c}{ Online news } & \multicolumn{3}{c|}{ Social networking sites } \\
\hline Valence & \multicolumn{3}{|c}{ Positive } & \multicolumn{2}{c}{ Negative } & \multicolumn{2}{c|}{ Positive } & \multicolumn{2}{c|}{ Negative } \\
\hline About & $P$ & $N P$ & $P$ & $N P$ & $P$ & $N P$ & $P$ & $N P$ \\
\hline $75 / 75$ & 6 & 2 & 2 & 6 & 6 & 2 & 2 & 6 \\
$75 / 50$ & 6 & 2 & 2 & 6 & 4 & 4 & 4 & 4 \\
$75 / 25$ & 6 & 2 & 2 & 6 & 2 & 6 & 6 & 2 \\
$50 / 75$ & 4 & 4 & 4 & 4 & 6 & 2 & 2 & 6 \\
$50 / 50$ & 4 & 4 & 4 & 4 & 4 & 4 & 4 & 4 \\
$50 / 25$ & 4 & 4 & 4 & 4 & 2 & 6 & 6 & 2 \\
$25 / 75$ & 2 & 6 & 6 & 2 & 6 & 2 & 2 & 6 \\
$25 / 50$ & 2 & 6 & 6 & 2 & 4 & 4 & 4 & 4 \\
$25 / 25$ & 2 & 6 & 6 & 2 & 2 & 6 & 6 & 2 \\
\hline
\end{tabular}

Note: For explanation of this table, see experimental condition 5.5 .

\subsection{Data Processing}

The data were collected and stored in an online database, which was exported to MatLab for intermediate computation and statistical processing in Predictive Analytics SoftWare (PASW). The initial selection between the candidates, which the participants made immediately following the demographic variables, was the point of departure for all further processing. All consecutive results were computed as differences between the preferred candidate and the non-preferred candidate defined by the initial selection. This avoided the arbitrary use of either candidate as a perspective choice and guaranteed that positive values meant reinforcement of the initial attitude and negative values meant attenuation of the initial attitude.

The implicit attitudes measures used were defined by Greenwald et al. (1998) and processed according to the recommended standard procedure with the exceptions stated below. Trials with latency longer than $1500 \mathrm{~ms}$ and shorter than $200 \mathrm{~ms}$ were eliminated and participants with fewer than 16 trials in each average were excluded. Eight participants were excluded using this criterion, leaving 131 participants. Error responses were re-calculated as mean latency of correct response plus a penalty of $600 \mathrm{~ms}$.

The outcome of the implicit attitude measures is a difference measure that is essentially an effect size represented by $d$. A positive value of $d$ represents favorable attitudes towards the 
preferred candidate, relative to his competitor, and a negative value of $d$ represents relatively unfavorable attitudes towards the preferred candidate. In normal cases, $d$-values range from approximately +1 to -1 , where values near 1 or -1 represent strongly felt attitudes and values near zero represents indifference. In the explicit attitude measurements, some participants responded stereotypically by marking the same response to all items. Therefore, participants were excluded if they had no difference scores greater than zero and no standard deviation greater than zero. Using this criterion, nine participants were excluded leaving a final total of 122 participants. To make explicit attitudes comparable to implicit attitudes in range and value, we computed the difference in average ratings of the candidates across adjective ratings divided by the common standard deviation. The scale showed satisfactory internal reliability (Cronbach's Alpha $=.81$ ).

For both implicit and explicit measurements, the difference between candidates in the premeasurement was subtracted from the differences between candidates in the post-measurement and this led to a change score. This score became the dependent variable by which the effect of the experimental conditions was measured. Content for each medium (i.e., online news and social networking sites) were varied and formed an independent variable resulting in two factors, see Table 1.

While reading the news items, participants estimated the effects of each item on their attitudes. They could respond by choosing one of three alternatives: change (the item changes my previous view of the candidate), indifference (the item does not affect my view of the candidate), and confirmation (the item strengthens my previous view of the candidate). For each of eight stimulus types (formed by crossing factors of media, valence and political candidate), a tally was kept on the number of responses in each response category. These data allowed us to examine whether there were any differences between the two types of media in the strength and persuasiveness of the items, see further 6.1 .

\section{Results}

\subsection{Manipulation Check and Validation}

The presentation of the candidates in the brief biographical sketches was designed to elicit attitudes along the left-right dimension in politics. This would allow participants to make a choice based on reasons beyond mere chance, although the evidence at that point would be extremely scanty. Therefore, we expected that participants' political sympathies and demographics would predict the initial vote. To test whether this functioned as intended, a binominal logistic regression was used, with candidate choice as the dependent variables and political sympathy as the independent variable along with age and gender as covariates. The results showed that voting was reliably predicted by the model, Nagelkerke $R^{2}=.40, \chi^{2}(4, N=122)=42.81, p<.001$. Political sympathy, age, and gender were all significantly related to voting in predicted directions. For example, votes in favor of the right-of-center candidate were cast by $55.3 \%$ in the LiberalConservative Alliance, and only $15.8 \%$ in the Red-Green Opposition. Thus, this initial manipulation functioned as intended.

Further, the consistency of voting with attitude measures and the construct validity of the attitude measures was measured. The first vote was significantly predicted by both explicit and implicit attitudes, Wilks' Lambda $=.58, \chi^{2}(2, N=122)=65.64, p<.001$, and the second only by the explicit attitude, Wilks' Lambda $=.56, \chi^{2}(1, N=122)=69.08, p<.001$. Correlations between the two types of attitudes were moderate, $r=.35$ in first measurement and $r=.25$ in the second, in accordance to general findings in the literature.

Addressing our concern that item effects could be confounded with media effects, participants' online responses to items were used as indicators of the strength of the items. In the analysis, the three possible responses were distributed in the same way in both types of media, $F(1,121)=.19$, $p=.67, \eta_{\mathrm{p}}{ }^{2}=.00$. Of the 16 items for each medium, on average 4.2 and 4.1 elicited the "change" 
response, 6.3 and 6.4 elicited the "indifference" response, 5.4 and 5.5 elicited the "confirmation" response. Thus, when judged in isolation, there were no overall differences between the two types of media in the strength and persuasiveness of the items. Therefore, any arising media difference can be ascribed to the context in which source became important.

\subsection{Influence of Media Type on Attitudes}

The influence of media was tested by looking at the influence on explicit attitudes, implicit attitudes and voting behavior. Two $3 \times 3$ between-subjects analyses of variance (ANOVA) were performed on explicit and implicit attitudes. Dependent variables were explicit and implicit attitude change (post-measurement minus pre-measurement) and independent variables were item distributions, i.e. the degree $(25,50$ or 75 per cent) to which the items (online news versus social networking sites) favored one candidate over the other.

Figure 1 shows the means of attitude changes as a function of information content. It was expected that attitude change (positive values meaning increased liking for the chosen candidate) to grow linearly with the proportion of content favoring the chosen candidate. The figure suggests that this may be the case when driven by information from online news, whereas social networking sites have no effect.

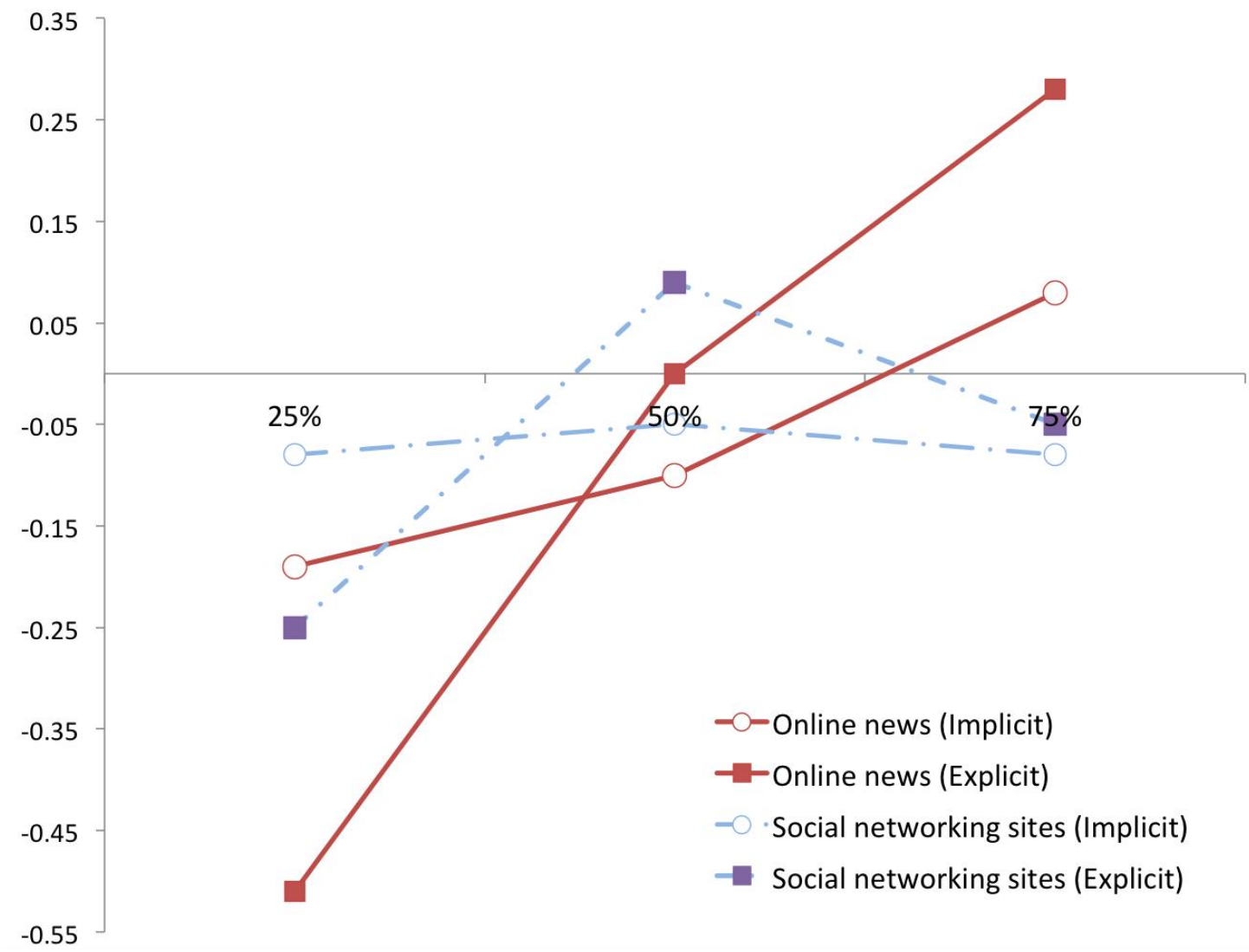

Figure 1: Attitude scores on the $y$-axis indicate increases in preference for initially chosen candidate after experimental treatment as a function of the proportion of favorable information and the source media type (online news or social networking sites).

A test of the explicit attitudes showed an effect of online news, $F(2,113)=9.25, p<.001, \eta_{p}{ }^{2}=$ .14 , which could be decomposed into a linear trend contrast that was reliably different from zero ( $C$ $=0.56 ; 95 \% \mathrm{Cl}: 0.30-0.82 ; p<.001)$, and a quadratic trend contrast, which did not differ from zero 
$(\mathrm{C}=-0.10 ; 95 \% \mathrm{Cl}:-0.35-0.15 ;$ N.S. $)$. The effect of information from social networking sites was not significant, $F(2,113)=2.09, p=.13, \eta_{p}^{2}=.04$. Concerning implicit attitudes, they showed a similar pattern. Information from online news had a significant effect, $F(2,113)=3.51, p<.05, \eta_{\mathrm{p}}{ }^{2}=.06$, and a breakdown revealed a significant linear trend contrast reliably different from zero $(C=0.20$; $95 \% \mathrm{Cl}: 0.05-0.35 ; p<.05)$, and a non-significant quadratic trend contrast, which did not differ from zero $(\mathrm{C}=0.05 ; 95 \% \mathrm{Cl}$ : $-0.10-0.20 ; \mathrm{N} . \mathrm{S}$.). Information from social networking sites showed no significant effect, $F(2,113)=.04, p=.96, \eta_{p}^{2}=.00$.

\subsection{Effects of Valence}

Using the participants' own estimates, each item was rated for its potential to bring about change in the attitudes toward the candidates. We expected negative items, e.g. items disclosing embarrassing or incriminating facts, or items citing bigoted or uninformed views expressed by the candidate to be more heavily weighted in shaping attitudes than their positive counterparts. Importantly, whether the type of media moderated a valence advantage was tested. Sensational information is probably believed only when backed by a trusted source, whereas the mundane can be accepted from any source. Both the negativity advantage and its modification by source type could be confirmed. As expected, negative items had a stronger influence than positive ones, $F(1,121)=59.68$, $p<.001, \eta_{p}^{2}=.33$. This difference was greater in online news (proportion of items judged to induce change: $\left.M_{\text {pos }}=.16 ; M_{\text {neg }}=.37\right)$ compared to social networking sites $\left(M_{\text {pos }}=.17 ; M_{\text {neg }}=.30\right)$, giving rise to an interaction effect, $F(1,121)=9.43, p<.01, \eta_{\mathrm{p}}{ }^{2}=.07$, see Figure 2. Media was not significant, $F(1,120)=3.58, p=.06, \eta_{\mathrm{p}}^{2}=.03$.

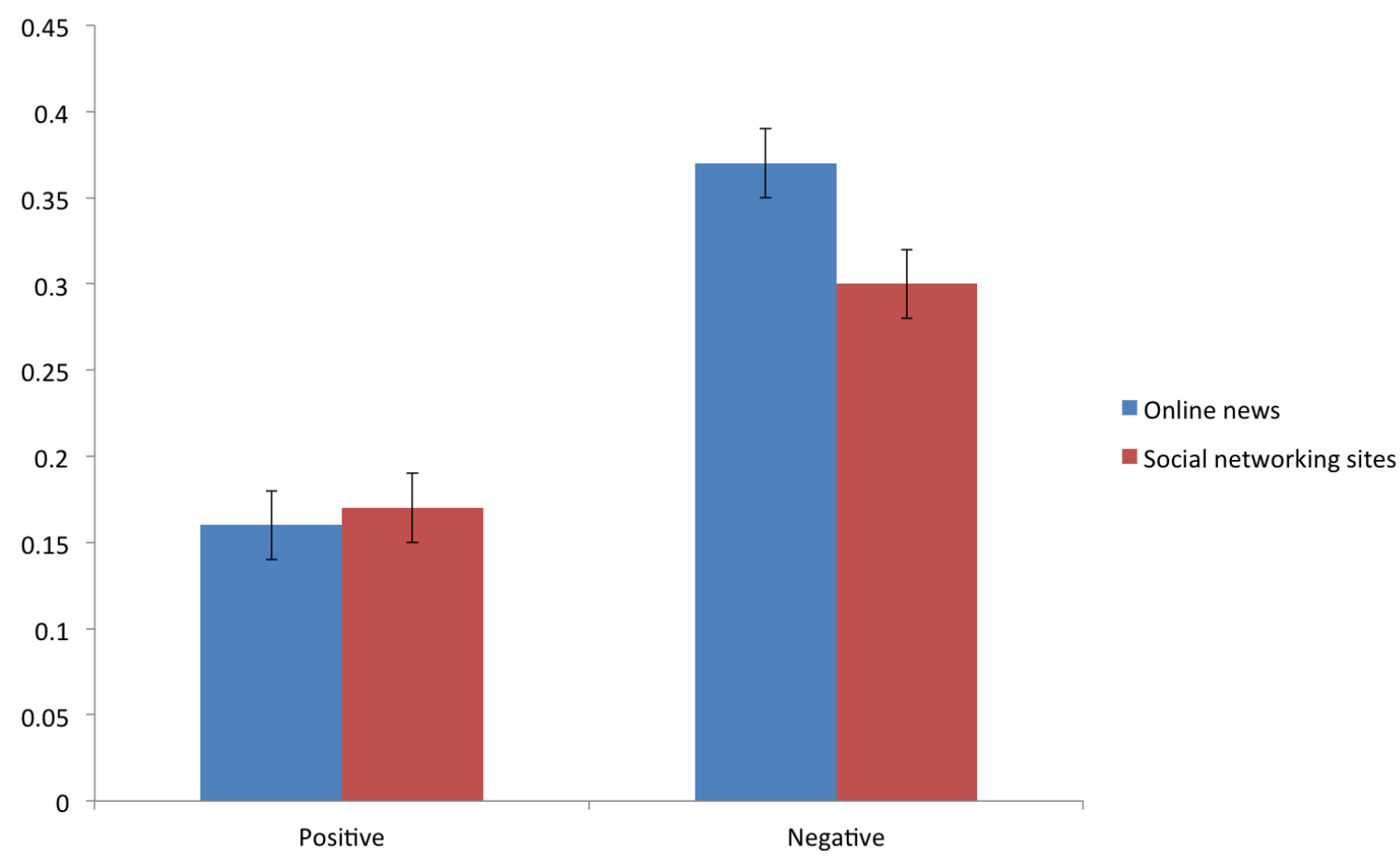

Figure 2: Effects of valence and source type on judged potential for change of preference.

\subsection{Voting Behavior}

The left-of-center candidate reached a $58 \%$ of the votes in the first round and $56 \%$ in the second. But beneath this slight net change, $20 \%$ of the participants had changed sides. This is not far from the theoretical maximum, because only $31 \%$ were in experimental conditions where the totality of information received was more in favor of the previously non-preferred candidate than of the 
preferred one. A binary categorization of participants into those who changed their votes versus those who did not was cross-tabulated against the experimental design factors. The factors were confined to levels $25 \%$ and $50 \%$, because the $75 \%$-level, in which favorable evidence is accumulated on the already preferred candidate, can have no measurable effect on the votes beyond that of the $50 \%$ condition.

Both factors showed effects on vote change (i.e. a change in votes), $\chi^{2}(1, N=89)=4.54, p<.05$ for online news and $\chi^{2}(1, N=89)=5.88, p<.05$ for social networking sites. Figure 3 illustrates the fact that unfavorable information, irrespective of source media type, increases the chance of switching sides. Expressed in another way, the $25 \%$ condition convinced $32 \%$ to abandon their previous favorite if the information came through online news, and $35 \%$ if the information came through social networking sites. Thus, social networking sites were not as ineffective as they appeared to be in the overall analysis. In the contended area, where allegiance to the initially preferred candidate is loosening its grip, social networking sites can have as large an effect as online news.

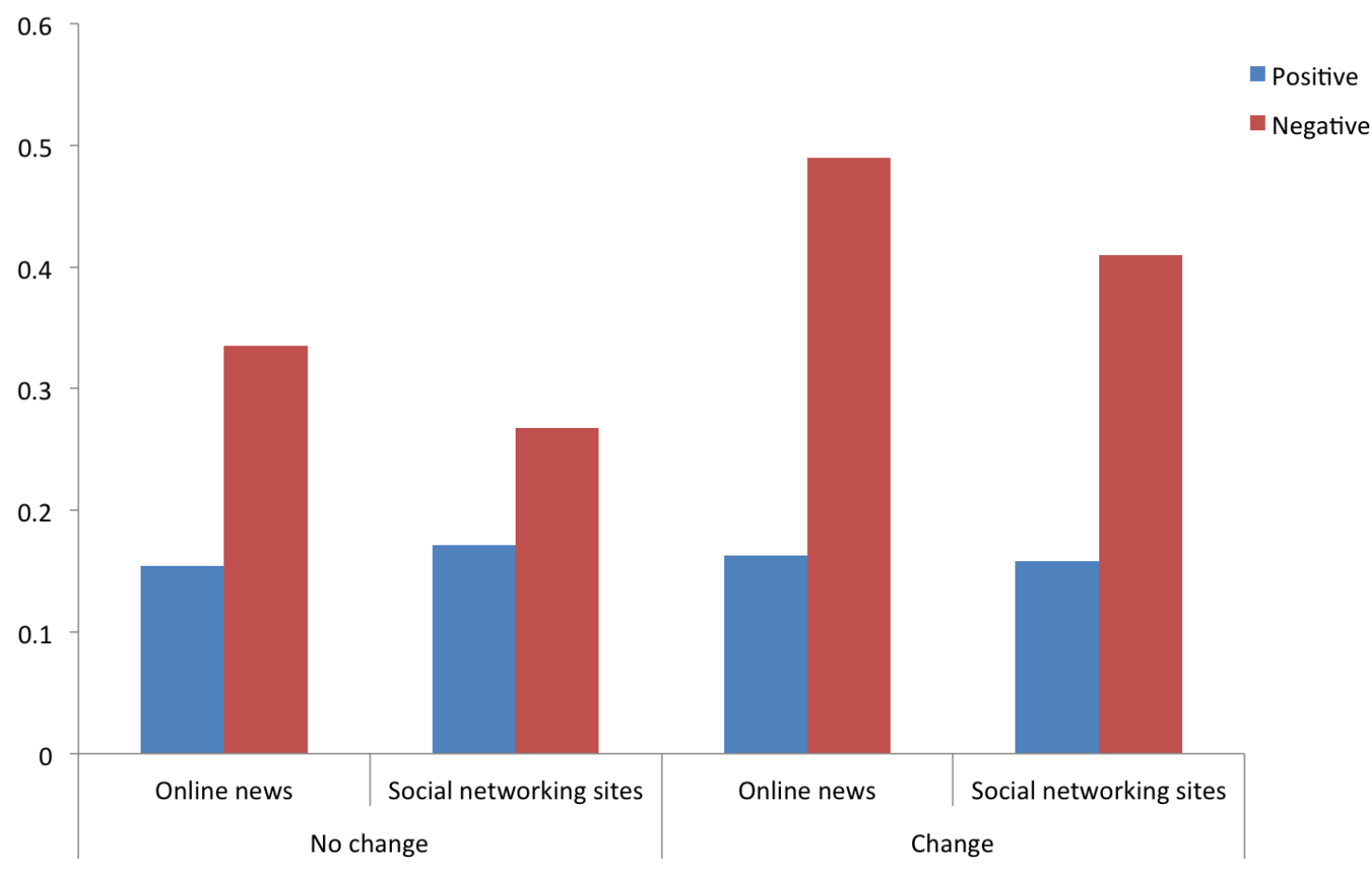

Figure 3: The number of changed votes (from pre- to post-measurement) as a function of experimental condition.

To further elucidate these results, the effect sizes of differences between levels of positive and negative information from online news and social networking sites were examined. As measured by Cohen's (1988) $d$, the effect size produced by online news for positive information was small (.28) and medium-sized (.51) for negative information. Similarly, for social networking sites, the effect size for positive information was negligible (.01) and for negative information, it was small (.28). A test of implicit attitude change showed a similar pattern where online news generated a negligible effect size for positive information (.08) and a small effect size for negative information (.20). Social networking sites had a negligible effect size for both positive (.08) and negative information (.09). 
The two types of media showed an impact on voting behavior and to examine the mediating effect of the two attitude variables on voting behavior, a binominal logistic regression was applied. The results showed a significant effect for explicit attitude change, Nagelkerke $R^{2}=.26, \chi^{2}(1, N=$ $122)=15.32, p<.001$, but not for implicit attitude change, Nagelkerke $R^{2}=.40, \chi^{2}(4, N=122)=$ $1.21, p=.27$. In summary, the results show that participants who received negative information from either type of media were more likely to change their explicit attitudes in a negative direction and as a consequence, to change their vote.

\section{Discussion and Conclusions}

Democracy is built on the assumption of a well-informed electorate. Matching the right to elect representatives is the duty to be informed about their qualities. People elect those who they believe to be better than their competitors. In judging this, they have to rely on, in most cases, publicly available information which comes in great abundance. Where information abounds, decisions halt and falter. Selecting which source to rely on is often both the first and the last step in acquiring knowledge. Our study inquires how voters do this in the political arena. It poses that question in the context of two types of digital media, online news and social networking sites.

To assess the effect of the two types of media on explicit and implicit attitudes as well as voting behavior, a web-based experiment mimicking a political election process was designed. Two fictitious candidates were pitted against each other in an ultra-compact campaign consisting of a stream of news items packaged into measured dosages of content favoring one candidate over the other. Campaign content was presented as brief text items purportedly from either prestigious online news sites such as New York Times or social networking sites such as Facebook and Twitter. Online news media was expected to have more credibility in the eyes of the participants, because their editorial processing seems to guarantee that certain standards are upheld. Of course, nothing precludes high quality content in social networking sites as well. Indeed, much of content there is formed by direct quotes from other media. But, even so, factors of selection and subjective framing in social networking sites often make it obvious that they make no claim to circumspection and objectivity. Perhaps because of this, social networking sites are perceived as less credible in comparison to online news media (Townera \& Dulioa, 2011).

The data showed that attitudes were formed in close agreement with the perceived trustworthiness of the information source. An analysis of the mean values of explicit and implicit attitude change as a function of the proportion of media content showed a linear effect for online news but none for social networking sites. In other words, a candidate reached increasing levels of both explicit attitudes (estimates of likeability, trustworthiness, etcetera.) and implicit attitudes (associations with good things) if the media content was in his favor, provided that the source was online news media. Social networking sites had no systematic influence. For a conclusion to be drawn from a negative, i.e. non-significant result, the statistical test must have sufficient power. There was an $80 \%$ chance of detecting a small effect (effect size 0.3 ) in our main analyses according to a power calculation (Faul, Erdfelder, Lang, \& Buchner, 2007). While there is a risk that social networking sites do have an effect that was overlooked, the risk seems small to take it.

Returning to the overarching question on the wisdom of the electorate, results so far have suggested a rational and sophisticated electorate. Source considerations seem to have been active in all stages of attitude formation, implicit as well as explicit. Awareness of perceived trustworthiness of the source penetrated cognitive as well as affective processing of the information given, as indicated by the results concerning explicit and implicit attitudes. A cognitive bias apparently applies to most information processing, viz. the advantage given to negative information over positive. Many scholars believe it is of evolutionary origin (Kahneman \& Tversky, 1979; Lau \& Pomper, 2002), as the price of ignoring a peril is prohibitive in comparison to the price of missing an opportunity. The inquiry here focused on whether this bias operated on political campaign information as well. In particular, does it operate on all media sources in the same way? Hypothetically, a critical observer might handle all information from less trustworthy sources with care, and do so with extra 
caution if the information is negative. They might do so out of a tacit knowledge of the potency of negativity. The more innocuous positive information would, in this scenario, undergo a less stringent examination.

In the data, negative news items weighed more heavily than positive ones, particularly when they appeared in online news compared to social networking sites. These findings support prior research studies demonstrating that negative stimuli hold stronger informational value than positive ones (e.g., Carraro, et al., 2010; Peeters \& Czapinski, 1990). The narrower band of the attitude spectrum containing the much sought-after swing vote, i.e. the range not yet cemented into steadfast loyalty, showed a different pattern of influences. Here, social networking sites had an influence at least on a par with online news, as seen in the examination of vote changing behavior.

When drawing practical conclusions, the findings support the alleged conventional wisdom that smearing one's opponent pays off better than bringing forth one's own political ideology. Admittedly, the meta-analytical review by Lau et al. (2007) has cast doubt on the proposition that negative campaigning pays off more than positive campaigning in terms of number of received votes. However, the review did find the cognitive effects of negative campaigns to be more durable and comprehensive than those of positive campaigns. The practical consequences of the results therefore need to be interpreted by both the findings of the review and by the recommendation to achieve efficiency through negative campaigning, i.e. to receive more votes.

Moreover, some methodological features limited the generalization of the findings; item content was not controlled in advance. Items were tailor-made for the medium and could therefore not be rotated through media conditions. Control after the fact cannot be compared to randomization, but it is definitely better than no control. The participants judged the impact of each item individually. Although online news items differed from social networking sites items both in length and depth, the data showed no differences between the two types of media and therefore any media differences that arises can be attributed to the context in which the source became significant. Another limitation of the study was the use of a discrete variable for vote change instead of a continuous one. This limited the ability to register a number of changes that may have occurred, for instance between implicit attitudes and voting. Some participants may have been positively affected in their implicit attitudes towards their favorable candidate but were not able to express this due to the discrete variable, leading to unchanged status quo.

It is important to note the time span during which the participants completed the experiment. Completion of the experiment varied between 15-20 minutes, compared to a regular political campaign that progresses over several months. A longer time span together with a more sensitive Implicit Association Test could have revealed stronger effects on implicit attitudes both for online news and social networking sites. This may be due to the tendency of implicit attitudes to form slowly over a long period of time, as pointed out by Greenwald, et al. (1998) and Rydell and McConnell (2006).

In contrast, a major strength of the study was a completely randomized between-subjects design. Each participant was randomly assigned to one of the experimental conditions and the role of the protagonist of each item was randomly assigned to the political candidates. Random assignment of items avoided the possible confounding of news item presentation with participant's media preferences.

This study contributes new findings about the effectiveness of online news and social networking sites in political campaigns. Social networking sites are considered by many to be the 'next big thing' in political campaigns in order to influence people's attitudes and ultimately collect votes. However, our data reveal that participants have a skeptical attitude towards social networking sites and were not influenced in their attitudes by information spread through these sources. Instead, information from online news influenced both their implicit and explicit attitudes. This suggests that online news issued by journalistic outlets still hold a strong position in political information dissemination. Furthermore, the results reveal the importance of negative information in media on attitudes and voting behavior. Specifically, negative news from online news and social networking sites was 
considered more important than positive ones. Those who received negative information from either type of media were more likely to change their explicit attitudes in a negative direction and as a consequence also change their vote. In conclusion, social networking sites have shown their usefulness as a means of mobilization in various protests, crowd-sourcing and viral distribution of information, but they have yet to find their role in political campaigns.

Future directions should take into account the limitations of the current study and investigate new aspects of social networking sites in political campaigns. For instance, to what extent does personal information about a political candidate in social networking sites influence attitudes, or in what way does increased familiarization with a political candidate in social networking sites influence vote persuasion.

\section{References}

Albrecht, S., Lubcke, M., \& Hartig-Perschke, R. (2007). Weblog campaigning in the German bundestag election 2005. Social Science Computer Review, 25(4), 504-520.

Ansolabehere, S. D., lyengar, S., \& Simon, A. (1999). Replicating experiments using aggregate and survey data: The case of negative advertising and turnout. American Political Science Review, 93(4), 901-909.

Arcuri, L., Castelli, L., Galdi, S., Zogmaister, C., \& Amadori, A. (2008). Predicting the vote: Implicit attitudes as predictors of the future behavior of decided and undecided voters. Political Psychology, 29(3), 369-387.

Bimber, B., \& Davis, R. (2003). Campaigning online: The Internet in the U.S. elections. . New York: Oxford University Press.

Boksem, M. A., Meijman, T. F., \& Lorist, M. M. (2005). Effects of mental fatigue on attention: An ERP study. Cognitive Brain Research, 25(1), 107-116.

Borins, S. (2009). From online candidate to online president. International Journal of Public Administration, 32(9), 753-758.

Campus, D., Pasquino, G., \& Vaccari, C. (2008). Social networks, political discussion, and voting in Italy: A study of the 2006 election. Political Communication, 25(4), 423-444.

Caprara, G. V., \& Zimbardo, P. G. (2004). Personalizing politics: A congruency model of political preference. American Psychologist, 59(7), 581-594.

Carlson, M. (2007). Blogs and journalistic authority. Journalism Studies, 8(2), 264-279.

Carraro, L., Gawronski, B., \& Castelli, L. (2010). Losing on all fronts: The effects of negative versus positive person-based campaigns on implicit and explicit evaluations of political candidates. British Journal of Social Psychology, 49(3), 453-470.

Castells, M. (2001). The Internet galaxy: Reflections on the Internet, business and society. Oxford: Oxford University Press.

Chaiken, S., \& Maheswaran, D. (1994). Heuristic processing can bias systematic processing: effects of source credibility, argument ambiguity, and task importance on attitude judgment. Journal of Personality and Social Psychology, 66(3), 460-473.

Cohen, J. (1988). Statistical power analysis for the behavioral sciences (2nd ed.). Hillsdale, NJ: Erlbaum.

Cunningham, W. A., Preacher, K. J., \& Banaji, M. R. (2001). Implicit attitude measures: Consistency, stability, and convergent validity. Psychological Science, 12(2), 163-170.

Daekyung, K., \& Johnson, J. (2006). A victory of the Internet over mass media? Examining the effects of online media on political attitudes in South Korea. Asian Journal of Communication, 16(1), 1-18.

Derzon, J. H., \& Lipsey, M. W. (2002). A meta-analysis of the effectiveness of mass-communication for changing substanceuse knowledge, attitudes, and behavior. In W. D. Crano \& M. Burgoon (Eds.), Mass media and drug prevention: Classic and contemporary theories and research (pp. 231 - 258). Mahwah, NJ: Lawrence Erlbaum Associates.

Faul, F., Erdfelder, E., Lang, A.-G., \& Buchner, A. (2007). G*Power 3: A flexible statistical power analysis program for the social, behavioral, and biomedical sciences. Behavior Research Methods, 39(2), 175-191.

Findahl, O. (2012). Swedes and the Internet 2012. Retrieved 19 December, 2012, from http://www.internetstatistik.se/ artiklar/english-version-of-swedes-and-the-internet/

Fridkin, K. L., \& Kenney, P. (2011). Variability in citizens' reactions to different types of negative campaigns. American Journal of Political Science, 55(2), 307-325.

Funk, C. L. (1999). Bringing the candidate into models of candidate evaluation. Journal of Politics, 61(3), 700-720.

Gil de Zuniga, H., Puig, I. A. E., \& Rojas, H. (2009). Weblogs, traditional sources online and political participation: an assessment of how the internet is changing the political environment. New media \& society, 11(4), 553-574

Glynn, C., Huge, M., Reineke, J., Hardy, B., \& Shanahan, J. (2007). When Oprah intervenes: Political correlates of daytime talk show viewing. Journal of Broadcasting \& Electronic Media, 51(2), 228-244.

Greenwald, A. G., McGhee, D. E., \& Schwartz, J. L. K. (1998). Measuring individual differences in implicit cognition: The implicit association test. Journal of Personality and Social Psychology, 74(6), 1464-1480.

Greenwald, A. G., Nosek, B. A., \& Banaji, M. R. (2003). Understanding and using the Implicit Association Test: I. An improved scoring algorithm. Journal of Personality and Social Psychology, 85(2), 197-216.

Hanson, G., Haridakis, P. M., Cunningham, A. W., Sharma, R., \& Ponder, J. D. (2010). The 2008 presidential campaign: Political cynicism in the age of Facebook, MySpace, and YouTube. Mass Communication and Society, 13(5), 584607.

Ifukor, P. (2010). "Elections" or "selections"? Blogging and twittering the Nigerian 2007 general elections. Bulletin of Science, Technology \& Society, 30(6), 398-414.

Jasperson, A. E., \& Fan, D. P. (2002). An aggregate examination of the backlash effect in political advertising: The case of the 1996 U.S. senate race in Minnesota. Journal of Advertising, 31(1), 1-12.

Jellison, W. A., McConnell, A. R., \& Gabriel, S. (2004). Implicit and explicit measures of sexual orientation attitudes: Ingroup preferences and overt behaviors among gay and straight men. Personality and Social Psychology Bulletin, 30(5), 629-642. 
Johnson, T. J., \& Kaye, B. K. (1998). Cruising is believing?: Comparing Internet and traditional sources on media credibility measures. Journalism and Mass Communication Quarterly, 75(2), 325-341.

Johnson, T. J., \& Kaye, B. K. (2010). Believing the blogs of war? How blog users compare on credibility and characteristics in 2003 and 2007. Media War and Conflict, 3(3), 315-333.

Johnson, T. J., Kaye, B. K., Bichard, S. L., \& Wong, W. J. (2007). Every blog has its day: Politically-interested Internet users' perceptions of blog credibility. Journal of Computer-Mediated Communication, 13(1), 100-122.

Kahneman, D., \& Tversky, A. (1979). Prospect theory: An analysis of decision making under risk. Econometrica, 47(2), 263292.

Kaid, L. L., \& Johnston, A. (2001). Videostyle in presidential campaigns: Style and content of televised political advertising. Westport, CT: Praeger/Greenwood.

Kalbfleisch, P. J. (2003). Communication Yearbook 27 (pp. 297-299). Mahwah, USA: Lawrence Erlbaum Associates Inc.

Katz, J. E., \& Rice, R. E. (2002). Social consequences of Internet use: Access, involve- ment, and interaction. Cambridge, MA: MIT Press.

Kononova, A., Alhabash, S., \& Cropp, F. (2011). The role of media in the process of socialization to American politics among international students. International Communication Gazette, 73(4), 302-321.

Larry, C., Mary, M. L., \& Richard, E. P. (2008). The consumption of online news: The relationship of attitudes toward the site and credibility. Journal of Internet Commerce, 7(4), 528-549.

Lau, R. R. (1985). Two explanations for negativity effects in political behavior. American Journal of Political Science, 29(1), 119-138.

Lau, R. R., \& Pomper, G. M. (2002). Effectiveness of negative campaigning in U.S. Senate Elections. American Journal of Political Science, 46(1), 47-66.

Lau, R. R., Sigelman, L., \& Rovner, I. B. (2007). The effects of negative political campaigns: A meta-analytic reassessment. Journal of Politics, 69(4), 1176-1209.

Mackay, J., \& Lowrey, W. (2007). The credibility divide: Reader trust of online newspapers and blogs. Paper presented at the the annual meeting of the International Communication Association.

Martin, P. (2008). The mass media as sentinel: Why bad news about issues is good news for participation. Political Communication, 25(2), 180-193.

McConnell, A. R., \& Leibold, J. M. (2001). Relations among the Implicit Association Test, discriminatory behavior, and explicit measures of racial attitudes. Journal of Experimental Social Psychology, 37(5), 435-442.

Mirandilla, M. G. P. (2009, December 8). Cybercampaigning for 2010: The use and effectiveness of websites and social networking sites as campaign platforms for the 2010 Philippine presidential election. Paper presented at the 4th Communication Policy Research: South Conference, Negombo, Sri Lanka.

Nevid, J. S., \& McClelland, N. (2010). Measurement of implicit and explicit attitudes toward Barack Obama. Psychology and Marketing, 27(10), 989-1000.

Peeters, G., \& Czapinski, J. (1990). Positive-negative asymmetry in evaluations: The distinction between affective and informational negativity effects. In W. Stroebe \& M. Hewstone (Eds.), European Review of Social Psychology (Vol. 1, pp. 33-60). Chichester: Wiley \& Sons Ltd.

Perugini, M. (2005). Predictive models of implicit and explicit attitudes. British Journal of Social Psychology, 44(1), 29-45.

Petty, R. E., Briñol, P., \& Priester, J. R. (2009). Mass media attitude change: Implications of the Elaboration Likelihood Model of persuasion. . In J. Bryant \& M. B. Oliver (Eds.), Media effects: Advances in theory and research (3 ed., pp. 125-164). New York: Routledge.

Pew Research Center. (2011). The Internet and Campaign 2010. Retrieved 5 December, 2012, from http://www.pewinternet .org/reports/2011/the-internet-and-campaign-2010/section-2/the-internet-and-political-news-sources.aspx

Pillai, R., Williams, E. A., Lowe, K. B., \& Jung, D. I. (2003). Personality, transformational leadership, trust, and the 2000 U.S. presidential vote. Leadership Quarterly, 14(2), 161-192.

Qing, Q., \& Oyedeji, T. (2011). Credibility perceptions of different types of weblogs among young adults. Global Media Journal, 11(19), 1-14.

Renshon, S. A. (1996). The psychological assessment of presidential candidates. New York: New York University Press.

Rydell, R. J., \& McConnell, A. R. (2006). Understanding implicit and explicit attitude change: A systems of reasoning analysis. Journal of Personality and Social Psychology, 91(6), 995-1008.

Schwartz, M. B., Vartanian, L. R., Nosek, B. A., \& Brownell, K. D. (2006). The influence of one's own body weight on implicit and explicit anti-fat bias. Obesity, 14(3), 440-447.

Shah, D. V., McLeod, J. M., \& Yoon, S. (2001). Communication, context, and community: An exploration of print, broadcast, and Internet influences. Communication Research, 28(4), 464-506.

Shapiro, M. A., \& Rieger, R. H. (1992). Comparing positive and negative political advertising on radio. Journalism Quarterly, 69(1), 135-145.

Skowronski, J. J., \& Carlston, D. E. (1989). Negativity and extremity biases in impression formation: A review of explanations. Psychological Bulletin, 105(1), 131-142.

Slater, M. K., \& Kelly, K. J. (2002). Testing alternative explanations for exposure effects in media campaigns: The case of a community-based, in-school media drug prevention project. Communication Research, 29(4), 367-389.

Sloman, S. A. (1996). The empirical case for two systems of reasoning. Psychological Bulletin, 119(1), 3-22.

Smith, E. R., \& DeCoster, J. (2000). Dual process models in social and cognitive psychology: Conceptual integration and links to underlying memory systems. Personality and Social Psychology Review, 4(2), 108-131.

Spiro, K. (2001). Public trust or mistrust? Perceptions of media credibility in the information age. Mass Communication and Society, 4(4), 381-403.

Sriram, N., \& Greewald, A. G. (2009). The Brief Implicit Association Test. Experimental Psychology, 56(4), 283-294.

Tolbert, C., \& Mcneal, R. S. (2003). Unraveling the effects of the Internet on political participation? Political Research Quarterly, 56(2), 175-185.

Tormala, Z. L., Briñol, P., \& Petty, R. E. (2006). When credibility attacks: The reverse impact of source credibility on persuasion. Journal of Experimental Social Psychology, 42(5), 684-691.

Townera, T. L., \& Dulioa, D. A. (2011). The Web 2.0 election: Does the online medium matter? Journal of Political Marketing, 10(1-2), 165-188. 
Trent, J. S., \& Friedenberg, R. V. (2002). Political campaign communication: Principles and practices. Westport, CT: Praeger.

Utz, S. (2009). The (potential) benefits of campaigning via social network sites. Journal of Computer-Mediated Communication, 14(2), 221-243.

Webster, D. M., \& Richter, L. (1996). On leaping to conclusions when feeling tired: Mental fatigue effects on impressional primacy. Journal of Experimental Social Psychology, 32(2), 181-196.

Wu, D. H., \& Dahmen, N. S. (2010). Web sponsorship and campaign effects: Assessing the difference between positive and negative web sites. Journal of Political Marketing, 9(4), 314-329.

Zhang, W., Johnson, T. J., Seltzer, T., \& Bichard, S. L. (2010). The revolution will be networked: The influence of social networking sites on political attitudes and behavior. Social Science Computer Review, 28(1), 75-92.

\section{About the Authors}

Montathar Faraon is a doctoral candidate in media technology at Södertörn University in Sweden. He earned a master degree in education with focus on computer science and psychology from Växjö University, Sweden in 2008. In addition, he has completed a master degree in psychology from University of Wisconsin - La Crosse, USA and University of North Carolina - Greensboro, USA in 2010. His research interests include social media, participatory processes, and public opinion.

Georg Stenberg is professor emeritus in psychology at Kristianstad University in Sweden. His Ph.D. work at Lund University concerned neuropsychology and physiological psychology. Later work expanded these interests into cognitive psychology, especially memory. Present research interests focus on episodic and semantic memory, face processing, memory for pictures versus words, and cognitive mechanisms in autism.

Mauri Kaipainen is professor in media technology at Södertörn University in Sweden. He studied education, musicology and cognitive science at the University of Helsinki and earned his Ph.D. in 1994. His current research agenda focuses on applications of perspectivism in participatory and co-creative applications of social media, and the thus implied concept of multiperspective media. 